\title{
Spectrum of skin adnexal tumors with eccrine and apocrine differentiation - A single institution study of 40 cases with clinicopathological correlation
}

\author{
Vijayan $\mathrm{P}^{1}$, Nayak $\mathrm{R}^{2}$ \\ ${ }^{1}$ Deptartment of Pathology, MES Medical College, Malappuram district, Kerala, India \\ ${ }^{2}$ Deptartment of Pathology, Yenapoya Medical College, Mangalore, Karnataka, India
}

\author{
Keywords: \\ Skin adnexa; \\ Eccrine and Apocrine \\ differentiation; \\ Hidradenoma; \\ Spiradenoma; \\ Cylindroma;
}

\begin{abstract}
Background: Adnexal skin tumors are relatively rare and present diagnostic difficulties in view of the endless morphological spectrum, complex nomenclature and incomplete knowledge of their histogenesis. Since pathologists encounter these lesions rarely, accurate sub classification of these can be challenging. This study intends to study skin adnexal tumors with eccrine and apocrine differentiation with emphasis on their histomorphology.
\end{abstract}

Materials and Methods: The present study is a five year retrospective study with comprehensive analysis of 40 cases of adnexal tumors of skin in a tertiary center in Karnataka, South India. These tumors were reclassified and subtyped according to WHO classification of skin tumors, 2006.

Results: Out the 62 cases of adnexal tumors studied, 40 were tumors with eccrine and apocrine differentiation ( $77 \%$ benign and $23 \%$ malignant). Hidradenoma was the most common tumor comprising $37 \%$ of all tumors and $45 \%$ of the benign tumors followed by spiradenoma, cylindroma and chondroid syringoma respectively. Head and neck region was the most common site of occurrence, and seventh decade was the most frequent age group of presentation. A definite female preponderance was noted. Pagets disease of the breast was the most common malignant tumor in this group comprising (10\%).

Conclusion: Histopathology is considered the gold standard in the diagnosis of these tumors and so a clear knowledge of the clinical presentation and histomorphology of these tumors is essential to make a correct diagnosis. A diagnostic logarithm based on histomorphology provides a logical approach in the subclassification of adnexal tumors.

\section{INTRODUCTION}

Appendageal tumors are neoplasms whose differentiation is towards one or more of the adnexal structures of the skin.

\section{Correspondence:}

Dr. Poornima Vijayan, $M D$

Department of Pathology, MES Medical College,

Malappuram District, Kerala, India

E-mail:poornima_vij@yahoo.co.in
Depending on their presumed origin, adnexal tumors are categorized into those with apocrine and eccrine, follicular and sebaceous differentiation. ${ }^{1}$ Skin adnexal neoplasms present as skin lesions that are difficult to distinguish clinically from one another. They can be solitary or multiple. They are typically multiple when they are associated with an inherited syndrome. ${ }^{2}$ 
Most skin adnexal tumors are benign, and local complete surgical excision is curative. A malignant counterpart of almost every skin adnexal tumors has been described. These tumors are rare, locally aggressive, and have the potential for nodal involvement and distant metastasis, with a poor clinical outcome. ${ }^{3}$

Diagnosing these lesions is difficult because of the wide spectrum of these tumors and their variants, their rarity, differentiation along two or more adnexal lines and their complicated nomencalature. ${ }^{1}$ The gold standard in diagnosis is histopathological examination of a skin biopsy. ${ }^{2}$

The present study lays emphasis on the clinicomorphological spectrum of adnexal skin tumors with eccrine and apocrine differentiation. The objectives of the present study was to study the spectrum of adnexal skin tumors with eccrine and apocrine differentiation with regards to the incidence, gender, age and site distribution along with histopathological features and to assess the significance of these clinical and histological parameters.

\section{MATERIALS AND METHODS}

The present study was conducted retrospectively over a period of five years, $2007-2012$ in the Department of Pathology at a tertiary center in Karnataka, South India. During this five year period, all excision biopsy specimens which had a diagnosis of skin adnexal origin was included in this study. This included both benign and malignant adnexal tumors of the skin. A total of 62 cases were retrieved and those tumors with eccrine or apocrine differentiation were studied. The clinical details were obtained from the hospital records and the requisition form that was received in the department of pathology. The slides and blocks were retrieved from the archives and multiple serial sections were taken for each biopsy and stained with routine haematoxylin and eosin stain. The slides were reviewed and were reclassified and subtyped as per WHO classification of skin tumors, 2006.

\section{RESULTS}

The present study is a comprehensive analysis of collective adnexal tumors of skin wherein 40 cases of skin adnexal tumors with eccrine and apocrine differentiation were studied over a period of 5 years. These tumors have been classified according to WHO classification and analyzed with regard to their age, sex, site, clinical presentation as well as their various histomorphologic patterns.

During this study period, 62 cases of adnexal skin tumors were collected and studied. Of these, $48(77 \%)$ were benign tumors and $14(23 \%)$ were malignant. While 27 (36\%) were males and $35(64 \%)$ were females as shown in Table 1. Tumors with eccrine and apocrine differentiation were the most common tumors encountered among the skin adnexal tumors ( 40 cases) accounting for $64 \%$ of the tumors.

The size of the tumor was less than $2 \mathrm{~cm}$ (greatest dimension) in $82 \%$ of the cases. In our study, all these tumors presented as solitary lesions except in one case, wherein, eccrine poroma coexisted with eccrine hidrocystoma in the same patient. Four cases of spiradenoma presented as painful papules. In the present study, only $11 \%$ of the cases $(6$ cases) showed concordance between the clinical and histopathological diagnosis. The diagnosis of a sebaceous cyst was found to be the most common clinical diagnosis encountered in our study (29\%).

Head and neck region was the most common site $(62 \%)$ of occurrence of tumors with eccrine and apocrine differentiation with scalp being the most common subsite. Among the malignant tumors, nipple was the most common site of involvement.

Among the tumors with apocrine and eccrine differentiation, Hidradenoma was the most common tumor in this study (40\%) among the benign tumors and Paget disease of the breast was the most common malignant tumor (11\%). There was a definite female preponderance in this category of tumors with the male female ratio being 0.38:1. Spiradenoma, closely followed by cylindroma were the other common tumors in this category. The salient histological features of all these tumors encountered in our study are enumerated in Tables 2-5, (fig.1-5).

One case each of eccrine hydrocystoma, syringocystadenoma papilliferum and hidradenoma papilliferum were also noted in our study. (fig.6, 7)

Table 1: Distribution of Tumors with Eccrine and Apocrine differentiation in the present study

\begin{tabular}{llll}
\hline $\begin{array}{l}\text { Tumors with Eccrine and } \\
\text { Apocrine differentiation }\end{array}$ & Males & Females & Total \\
\hline Hidrocystoma & - & 1 & 1 \\
\hline $\begin{array}{l}\text { Poroma } \\
\text { Syringocystadenoma Papil- } \\
\text { liferum }\end{array}$ & - & 3 & 3 \\
\hline Hidradenoma & 4 & 11 & 1 \\
\hline Spiradenoma & 2 & 3 & 5 \\
Cylindroma & 1 & 3 & 4 \\
\hline Chondroid Syringoma & 1 & 2 & 3 \\
\hline Hidradenoma Papillifeum & 1 & - & 1 \\
\hline Eccrine carcinoma & 1 & & 1 \\
\hline $\begin{array}{l}\text { Pagets disease of breast } \\
\text { Extramammary Pagets } \\
\text { disease }\end{array}$ & 1 & 1 & 4 \\
\hline Total & $\mathbf{1 1}$ & $\mathbf{2 9}$ & $\mathbf{4 0}$ \\
\hline
\end{tabular}




\begin{tabular}{lc}
$\begin{array}{l}\text { Table 2: Salient histological features of Hidradenoma } \\
\text { encountered in our study }\end{array}$ \\
\hline Histologic features & No of cases (\%) \\
\hline Location in deep dermis & $15(100)$ \\
\hline Circumscribed & $15(100)$ \\
\hline Predominantly solid & $14(93.3)$ \\
\hline Solid-cystic & $7(46.6)$ \\
\hline Squamoid pattern & $9(60)$ \\
\hline Cystic change (focal) & $3(20)$ \\
\hline Clear cells & $7(46.6)$ \\
\hline Two cell population & $11(73.3)$ \\
\hline Foreign body reaction & $2(13.3)$ \\
\hline Pigmentation & $1(6.7)$ \\
\hline Glandular pattern & $1(6.7)$ \\
\hline
\end{tabular}

Table 3: Salient histological features of Spiradenoma en countered in our study

\begin{tabular}{lc}
\hline Histologic features & No of cases (\%) \\
\hline Location in deep dermis & $5(100 \%)$ \\
\hline Circumscribed & $5(100 \%)$ \\
\hline Predominantly solid & $5(100 \%)$ \\
\hline Solid-cystic & $2(40 \%)$ \\
\hline Lobular pattern & $4(80 \%)$ \\
\hline Cystic change (focal) & $3(60 \%)$ \\
\hline Two cell population & $5(100 \%)$ \\
\hline Pink hyaline material & $3(60 \%)$ \\
\hline Lymphocytic infiltration & $2(40 \%)$ \\
\hline Pigmentation & $1(20 \%)$ \\
\hline Glandular pattern & $1(6.7)$ \\
\hline
\end{tabular}

Table 4: Salient histological features of Cylindroma encountered in our study

\begin{tabular}{|lc}
\hline Histologic features & No of cases (\%) \\
\hline Location in deep dermis & $4(100 \%)$ \\
\hline Circumscribed & $4(100 \%)$ \\
\hline Predominantly solid & $4(100 \%)$ \\
\hline Islands of basaloid cells & $4(100 \%)$ \\
\hline Jig-saw puzzle pattern of arrangement & $4(100 \%)$ \\
\hline PAS positive thick hyaline sheath & $3(75 \%)$ \\
\hline Two cell population & $4(100 \%)$ \\
\hline Small tubular lumina (focal) & $2(50 \%)$ \\
\hline
\end{tabular}

Pagets disease of breast was the most common malignant tumor in this group. Maximum incidence was found in females of the $6^{\text {th }}$ and $7^{\text {th }}$ decades of life. All the cases presented as eczematous tender nipple lesions. All the cases had an underlying invasive carcinoma of the breast and one case had an associated carcinoma-in-situ component. The histological features of 4 cases of pagets disease of breast encountered in our study have been enumerated in Table.6. (fig.8)
Table 5: Salient histological features of Chondroid Syringoma encountered in our study

\begin{tabular}{lc}
\hline Histologic features & No of cases (\%) \\
\hline Location in dermis & $3(100 \%)$ \\
\hline Well Circumscribed lesion & $3(100 \%)$ \\
\hline Solid & $3(100 \%)$ \\
\hline Epithelial elements arranged as ducts, tubules, cords & $3(100 \%)$ \\
\hline Eccrine type glands & $3(100 \%)$ \\
\hline Chondromyxoid stroma & $3(100 \%)$ \\
\hline
\end{tabular}

Table 6: Salient histological features of Pagets disease of Breast encountered in our study

\begin{tabular}{|lc}
\hline Histologic features & No of cases (\%) \\
\hline Neoplastic cells confined to the epidermis & $4(100 \%)$ \\
\hline Extension beyond the epidermis & $2(50 \%)$ \\
\hline Cells with Large nuclei and prominent nucleoli. & $4(100 \%)$ \\
\hline Abundant Pale to amphophilic cytolplasm & $4(100 \%)$ \\
\hline Perivascular lymphocytic infiltrate & $3(75 \%)$ \\
\hline Underlying Infiltrating ductal carcinoma - NOS & $4(100 \%)$ \\
\hline PAS positivity in the neoplastic cells & $2(50 \%)$ \\
\hline Associated DCIS & $1(25 \%)$ \\
\hline
\end{tabular}

Extramammary Pagets Disease was the second most common tumor in the malignant category and also accounting for $6 \%$ of total tumors with eccrine and apocrine differentiation. The age of incidence was the 6th and 7th decades. One case presented with a scrotal eczematous plaque with erosive ulceration in a 65 year old male and the other presented as a perianal erythematous eczematoid lesion in a 58 year old female. (fig.9)

\section{DISCUSSION}

Skin adnexal tumors are relatively rare and hence uncommonly encountered in routine pathology practice. As a result, many aspects of these tumors continue to elude us. Further, difficulty also arises from the fact that most of these tumors have an endless morphologic spectrum, which is further compounded by the incomplete knowledge of their histogenesis. $^{3}$

The first case of mixed tumors was reported by $\mathrm{Nissau}^{3}$ and subsequently there have been several studies in western literature. ${ }^{3,4}$ However, in the Indian scenario, studies in this area have been few, and most often case reports or studies on individual tumors. Reddy et $\mathrm{al}^{5}$ reported a series of 85 cases of skin adnexal tumors and Vaishanav and Dharkar ${ }^{6}$ published a series of 48 cases. Parate et al reported a large series of 120 cases of skin adnexal tumors. ${ }^{7}$ More recently, $\mathrm{Nair}^{8}$ has published a 3 year retrospective study of 33 cases of skin adnexal tumors in a tertiary care centre in South India and Saha et $\mathrm{al}^{9}$ reported a series of 23 cases of adnexal skin tumors over a period of 1 year from a tertiary care centre in 


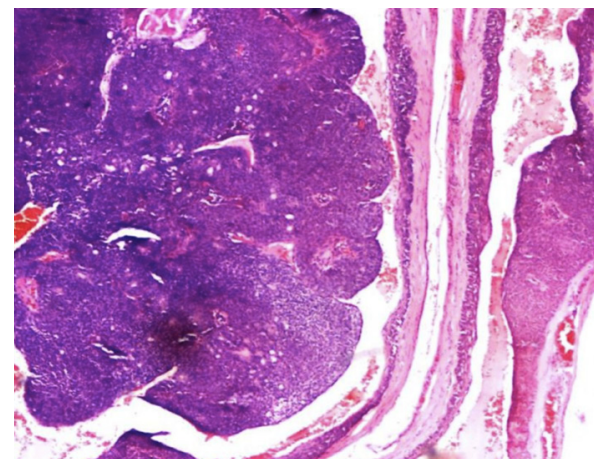

Figure 1A: Nodular hidradenoma showing prominent clear cell component (HE Stain, X40).

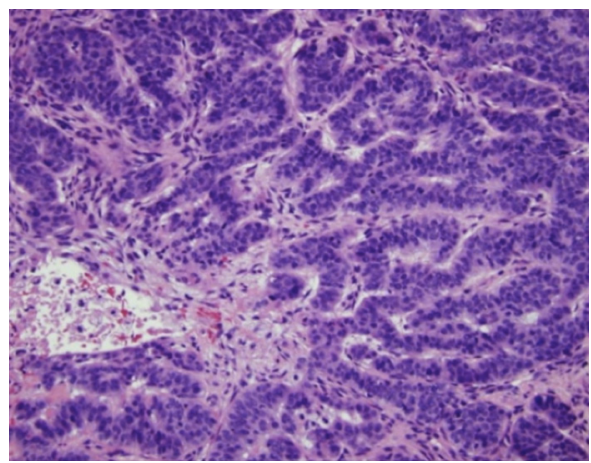

Figure 2: Anastomosing cords of tumor cells in spiradenoma (HE Stain, X40).

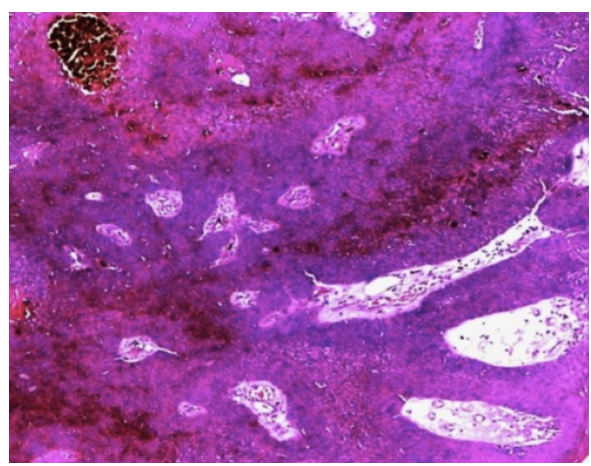

Figure 4: Poroma shown connection of tumor with the epidermis with foci of pigmentation (HE Stain, X4).

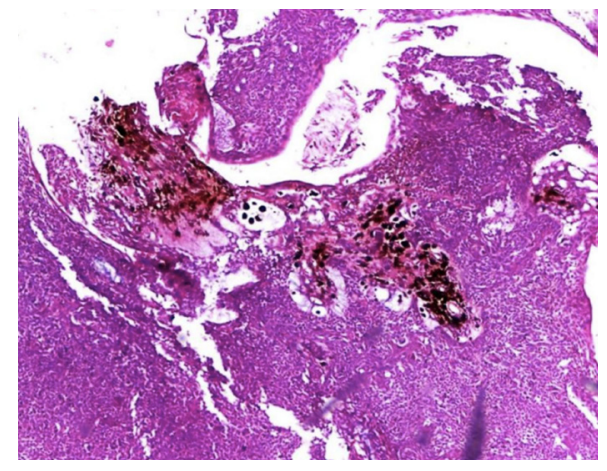

Figure 1B: Nodular hidradenoma with foci of pigmentation (HE Stain, X40).

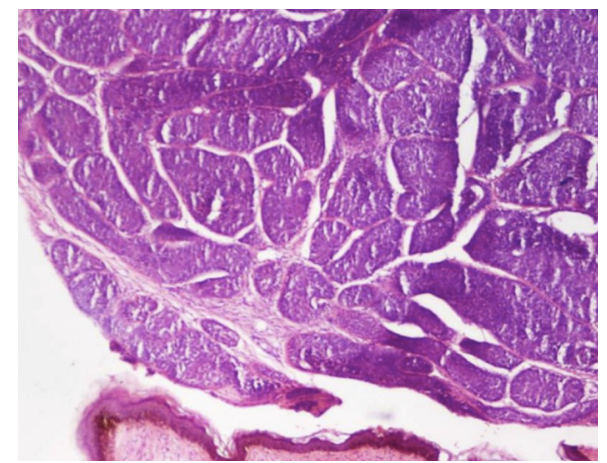

Figure 3: Cylindroma with jig-saw puzzle appearance of tumor cell islands separated by thick hyaline sheath (HE Stain, X4).

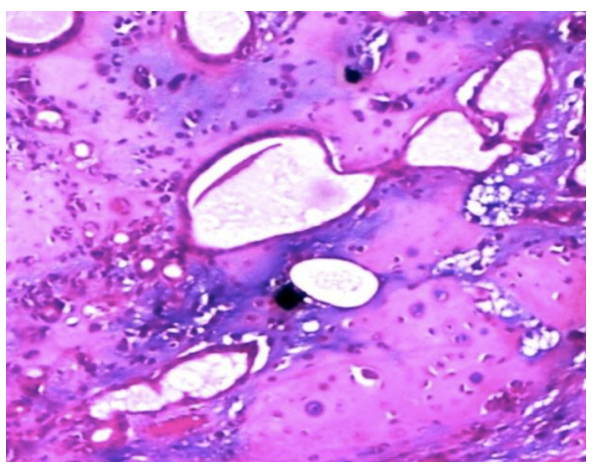

Figure 5: Chondroid syringoma showing chondromyxoid matrix and ducts (HE Stain, $\mathrm{X} 40$ ).
Eastern India.

Apocrine differentiation can be tentatively recognized by decapitation secretion, if present. Eccrine differentiation is characterized by ductal or tubular formation. But the mere presence of ducts cannot be conclusively used to determine whether a lesion exhibits eccrine or eccrine secretion because eccrine and apocrine ducts are indistinguishable except for the anatomic relationship to follicles displayed by apocrine structures ${ }^{3}$.
Hidradenoma was the most common tumor among the eccrine group of tumors and also the most frequent overall tumor in our study. The incidence was comparable to the studies by Reddy et at ${ }^{5}$ and Vaishnav and Dharkar. ${ }^{6}$ There was a female preponderance in our study. This was in contrast to the study by Reddy et $\mathrm{al}^{5}$ who documented a male preponderance. In the present study, most cases involved the head and neck region (72.7\%) although it is said to have no preferred site in the published literature. Although regarded as benign, nodular hidradenoma can recur after inadequate 


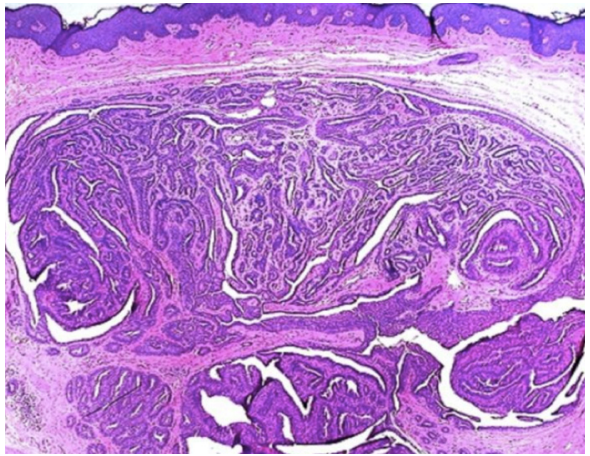

Figure 6: Hidradenoma papilliferum presenting as a vaginal papule (HE Stain, $4 \mathrm{X})$.

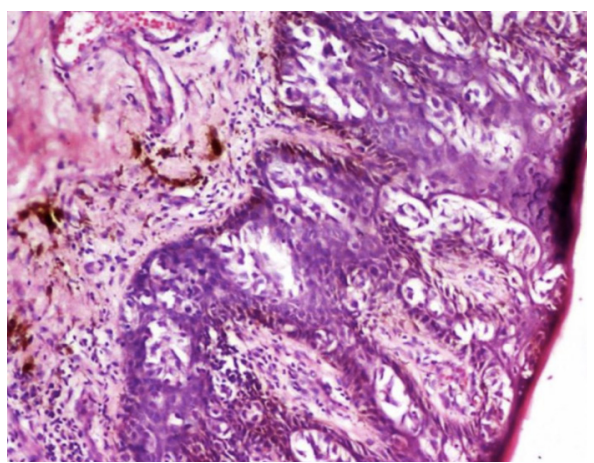

Figure 8: Pagets disease of breast showing large neoplastic cells with prominent nucleoli in the epidermis (HE Stain, X10).

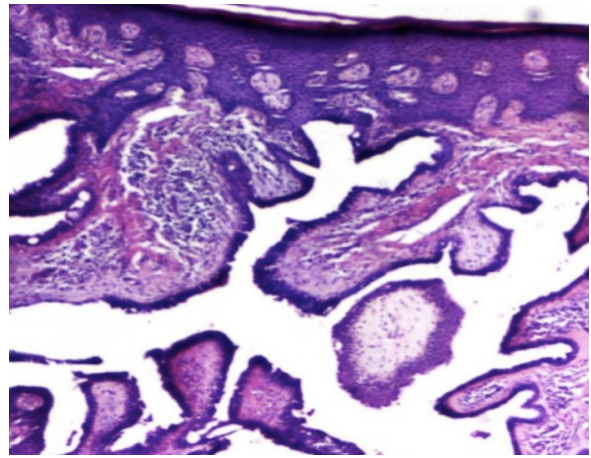

Figure 7: Syringocystadenoma papilliferum with papille and plasma cell infiltration in stroma (HE Stain, 40X).

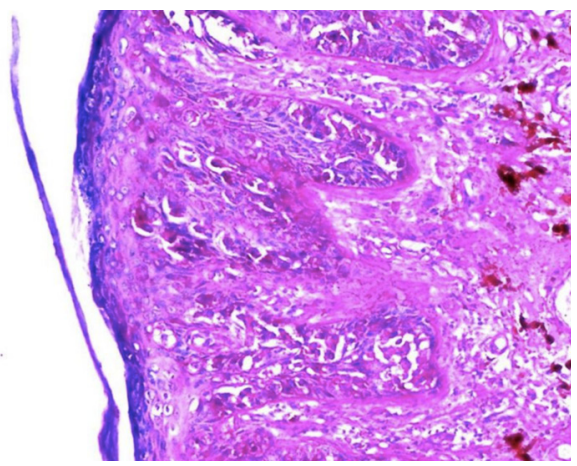

Figure 9: PAS positive neoplastic cells in a case of extramammary pagets disease of the scrotum (HE Stain, X10) excision. The salient histological features are highlighted in Table 2. These finding are in concordance with published literature. A recent study by Bevinahalli et a $1^{10}$ of 15 cases of nodular hidradenoma showed a similar age range and histological features as the present study.

Spiradenoma, cylindroma, chondroid syringoma and poroma were next in the order of frequency in the benign category in this study. The age at presentation, site and female preponderance noted in our study was in concordance with the study by Reddy et $\mathrm{al}^{5}$ who also reported similar findings. There have been reports of associations between spiradenoma and cylindroma in western literature. ${ }^{11,12}$ No such associations were noted in this study. The salient histological features of both these tumors are highlighted in Table.3-5 and they were in general concordant with published literature.

The WHO classification of skin tumors 2006 has classified Paget disease of breast under Skin Appendageal Tumors Malignant tumors with eccrine and apocrine differentiation. ${ }^{1}$ So going by this classification, in the present study, we documented 4 cases of Paget disease of the breast which accounted for $7.2 \%$ of all adnexal tumors and also the most common malignant adnexal tumor (28.5\%).

In 1874, Sir James Paget first described 15 cases of a chronic eczematous eruption of the nipple and areola and noted that mammary cancer developed in all patients within two years. The term Paget disease (PD) was coined in 1889 by Radcliffe Crocker when he described a morphologically and histologically similar eruption affecting the penis and scrotum. Paget disease of the breast and extramammary Paget disease are intraepidermal adenocarcinomas characterized by large atypical and pale staining cells scattered throughout the epidermis either as single cells or in small clusters. ${ }^{12}$ None of the other studies used here for comparison purposes have documented this tumor. The salient histological features are highlighted in Table. 6

Although malignant adnexal tumors are extremely rare, it is important to be able to recognize them. Features suggestive of malignancy include asymmetry of the lesion, infiltrative margins, cytonuclear atypia, significantly increased mitotic activity and irregular arrangement of neoplastic cells. ${ }^{1}$ One such case of recurrent eccrine carcinoma in a 55 year old male was encountered in our study. 


\section{Summary:}

The following conclusions were drawn from the present study.

- Adnexal skin tumors are relatively rare tumors.

- Morphological assessment was the most important criteria in the classification of adnexal tumors and the tumors were categorized based on the predominant morphological component.

- Benign adnexal skin tumors by far outnumbered the malignant ones.

- Tumors with eccrine and apocrine differentiation formed the largest group in this study with Hidradenoma being the most common individual tumor.

- A definite female preponderance was noted

- Head and neck was the most common site of involvement.

- Majority of the benign adnexal tumors occurred in the $4^{\text {th }}$ decade and the malignant adnexal tumors occurred in the 6th decade.

- Most of the time, the clinical diagnosis did not correlate with the histopathological diagnosis.

- Majority of the tumors were solitary tumors and no syndromic associations were noted in this study..

\section{CONCLUSION}

Thus, histopathology can be considered the gold standard in the diagnosis of adnexal skin tumors and morphological assessment is the most important criteria in evaluating skin adnexal tumors. A diagnostic logarithm based on morphological characters alone provides an orderly and logical approach in the subclassification of adnexal tumors as histopathology is still considered the gold standard in the diagnosis of these tumors. A large majority of these tumors are benign and complete excision is curative in most cases.

\section{REFERENCES}

1. LeBoit PE, Appendageal Tumors. In: LeBoit PE,Burg G, Weedon D, Sarasin A, editors. Pathology and genetics of skin tumors. World Health organization classification of tumors. Lyon,France: IARC Press;2006.123-6pp.

2. Lee DA, Grossman ME, Schneiderman P, Celebi JT. Genetics of skin appendage neoplasms and related syndromes. J Med Genet 2005:42;811-9. Crossref

3. Alsaad Ko, Obaidat NA, Ghazarian D. Skin adnexal neoplasms-part
I: an approach to tumors of the pilosebaceous unit. J Clin Pathol 2007:60;129-44. Crossref

4. Obaidat NA, Alsaad KO, Ghazarian D. Skin adnexal neoplasms-part II: An approach to tumors of cutaneous sweat glands. J Clin Pathol 2007:60;145-59. Crossref

5. Reddy MK, Veliath AJ, Nagarajan S, Aurora AL. A clinicopathological study of adnexal tumors of the skin. Indian J Med Res 1982;75:8829 .

6. Vaishnav VP, Dharkar P. adnexal tumors of skin. Indian J Pathol Bacteriol 1974;17:882-9.

7. Parate SN, Chahande RB, Nayak SP, BoBhate SK. Adnexal tumors of skin. Indian J dermatol 1998;43:58-60.

8. Nair PS. A clinicohistopathological study of skin appendageal tumors. Indian J Dermatol Venereol Leprol 2008;74;550. Crossref

9. Bevinahalli N, Nandeesh Bn, Rajalakshmi TT. A study of the Histopathologic spectrum of nodular hidradenoma. Am J Dermatopathol.2012;34:461-70. Crossref

10. Klein W, Chan E, Seykora JT. Tumors of the epidermal appendages. In:Elder De, Elentsas R, Johnson BL Jr,Murphy GF, editors. Lever's Histopathology of the skin. 9th ed. Philadelphia: Lippincott Williams and Wilkins; 2005.867-926pp.

11. McNiff J, McCalmont TH, Requena L et al. Appendageal tumors Benign tumors with apocrine and eccrine differentiation. In:LeBoit PE, Burg G, Weedon D, Sarasin A, editors. Pathology and genetics of skin tumors. World Health organization classification of tumors. Lyon,France: IARC Press;2006.141-53pp.

12. Requena L, Kutzner $\mathrm{H}$, Hurt MA, et al. Appendageal tumors - Malignant tumors with apocrine and eccrine differentiation. In:LeBoit PE, Burg G, Weedon D, Sarasin A, editors. Pathology and genetics of skin tumors. World Health organization classification of tumors. Lyon, France: IARC Press;2006.127pp. 